\title{
Adhesion, Proliferation, and Osteogenic Differentiation of a Mouse Mesenchymal Stem Cell Line (BMC9) Seeded on Novel Melt-Based Chitosan/Polyester 3D Porous Scaffolds
}

\author{
ANA RITA COSTA-PINTO, B.Sc., ${ }^{1,2, *}$ ANTÓNIO JOSÉ SALGADO, Ph.D., ${ }^{1,2, *}$ \\ VITOR MANUEL CORRELO, B.Eng., 1,2 PAULA SOL, B.Eng., 1,2 \\ MRINAL BHATTACHARYA, Ph.D., ${ }^{3}$ PIERRE CHARBORD, Ph.D., ${ }^{4}$ RUI LUIS REIS, Ph.D., ${ }^{1,2}$ \\ and NUNO MELEIRO NEVES, Ph.D. ${ }^{1,2}$
}

\begin{abstract}
The aim of the present work was to study the biological behavior of a mouse mesenchymal stem cell line when seeded and cultured under osteogenic conditions onto novel processed melt-based chitosan scaffolds. Scaffolds were produced by compression molding, followed by salt leaching. Scanning electron microscopy (SEM) observations and $\mu \mathrm{CT}$ analysis showed the pore sizes ranging between 250 and $500 \mu \mathrm{m}$ and the interconnectivity of the porous structure. The chitosan-poly(butylenes succinate) scaffolds presented high mechanical properties, similar to the ones of trabecular bone (E1\% $~ 75 \mathrm{MPa})$. Cytotoxicity assays were carried out using standard tests (accordingly to ISO/EN 10993 part 5 guidelines), namely, MTS test with a $24 \mathrm{~h}$ extraction period, revealing that $\mathrm{L929}$ cells had similar metabolic activities to that obtained for the negative control. Cell culture studies were conducted using a mouse mesenchymal stem cell line (BMC9). Cells were seeded onto the scaffold and allowed to proliferate for 3 weeks under osteogenic conditions. SEM observations demonstrated that cells were able to proliferate and massively colonize the scaffolds structure. The cell viability assay MTS demonstrated that BMC9 cells were viable after 3 weeks of culture. The cells clearly evidenced a positive differentiation toward the osteogenic lineage, as confirmed by the high ALP activity levels. Moreover, energy dispersive spectroscopy (EDS) analysis revealed the presence of $C a$ and $P$ in the elaborated extracellular matrix (ECM). These combined results indicate that the novel melt-based chitosan/polyester scaffolds support the adhesion, proliferation, and osteogenic differentiation of the mouse MSCs and shows adequate physicochemical and biological properties for being used as scaffolds in bone tissue engineering-related strategies.
\end{abstract}

\section{INTRODUCTION}

$\mathbf{T}$ HE LAST 15 YEARS HAVE WITNESSED the emergence of a novel multidisciplinary field of science called tissue engineering that has been in the forefront of a new wave of therapeutic/regenerative approaches for a variety of tissues, including bone. Its main purposes are production of tissues and organs substitutes/equivalents that can replace or restore the natural features and physiological functions of natural tissues in vivo. ${ }^{1,2}$

\footnotetext{
13B's Research Group-Biomaterials, Biodegradables and Biomimetics, Department of Polymer Engineering, University of Minho, Campus de Gualtar, Braga, Portugal.

${ }^{2}$ PT Government Associated Laboratory, Institute for Biotechnology and Bioengineering (IBB), Braga, Portugal.

${ }^{3}$ Department of Biosystems Engineering, University of Minnesota, St. Paul, Minnesota.

${ }^{4}$ Department of Hematology, Université François Rabelais in Tours, France.

*These authors contributed equally to this work.
} 
The most common approach used in the bone tissue engineering field is based on the seeding of cells with osteogenic potential, commonly mesenchymal stem cells, on 3D scaffolds followed either by direct implantation on the injury site or by an in vitro culturing period upon which the cells/ scaffold construct is implanted. ${ }^{3}$ Ultimately, these so-called bone tissue engineering constructs should have two main functions when implanted in vivo ${ }^{4-6}$ : (1) provide structural support until the neotissue can assure it by itself and (2) promote osteoinduction, meaning, in a simplistic way, the promotion of migration and differentiation of mesenchymal stem and osteoprogenitor cells, which later will lead to new bone formation. From the lines above, it can be clearly concluded that 3D scaffolds play a major role within any bone tissue engineering concept. Ideally these temporary scaffolds should be porous in order to accommodate cell growth and facilitate both tissue regeneration and vascularization. ${ }^{1,2,7}$ Further, they should also be biocompatible, be mechanically stable under loads, and have a physiologic biodegradation rate similar to the cell/tissue growth rates. ${ }^{1,2,7,8}$

Up to now, several materials, such as titanium alloys, ${ }^{9-11}$ ceramics, ${ }^{12-14}$ and biodegradable polymers,${ }^{15-18}$ have been used to obtain these 3D structures. Among those materials and due to their intrinsic characteristics, biodegradable polymers are those that have been used more frequently. The most widely used are poly $(\alpha$-hydroxy acids), such as poly (lactic acid), poly(glycolic acid), and their copolymers, because they have been already accepted by regulatory agencies. In spite of the fact that these materials have been thoroughly studied and extensively used in the clinical practice, it is also true that upon degradation they release acidic by-products, which may trigger inflammatory responses and compromise the needed integration by the host tissue. ${ }^{19,20}$

Therefore, there is an urgent need for the development of new biomaterials with scaffolding potential for bone tissue engineering. It is in this context that natural-based polymers have been put forward in the last few years. Within this group, the polysaccharides, like starch, ${ }^{20-22}$ and chitosan, ${ }^{23-29}$ have been highlighted as the most promising, as they may act as analogs of polysaccharides present in vivo and adopt their roles. ${ }^{27}$ An example of such affinity is the structural similarity observed between chitosan and glycosaminoglycans. ${ }^{28} \mathrm{Sev}-$ eral reports about chitosan, ${ }^{23-29}$ the alkaline deacetylated product of chitin, have shown that this polymer might have a range of interesting properties, from biodegradability to biocompatibility, considered to be suitable for bone tissue engineering scaffolding. Nevertheless, chitosan still presents a challenge when compared to other materials, that is, the inability of being processed by means other than by solventbased technology, which frequently leads to the development of scaffolds with poor mechanical properties and insufficient control of its morphology.

Since 2005, we have developed a new concept based on the development of thermoplastic chitosan polymers. ${ }^{30-33}$ This was achieved by melt-blending chitosan with different aliphatic polyesters, poly(caprolactone) (PCL), poly(butyl- enes succinate) (PBS), poly(butylene terephthalate adipate) (PBTA), and poly(butylene succinate adipate) (PBSA). By doing this, we conjugated the favorable biological properties of chitosan with the predictable degradative behavior of the aliphatic polyesters. Further information on the physical and chemical properties of these materials can be found in the reports of Correlo et al..$^{30-33}$

The present study reports on the morphology, mechanical properties, cytocompatibility, cell proliferation, and osteogenic differentiation of a mesenchymal stem cell line (BMC9) on novel compression molding/salt leaching scaffolds based on blends of chitosan with PCL, PBS, PBTA, and PBSA. Results have showed that the developed scaffolds had the adequate mechanical properties. Further, they disclosed a noncytotoxic behavior and simultaneously supported the growth and osteogenic differentiation of mouse mesenchymal stem cells within its structure.

\section{MATERIALS AND METHODS}

\section{Scaffolds production and processing}

Chitosan was melt blended with several biodegradable polyesters for the first time by our group ${ }^{30}$ using a twin screw extruder with the purpose of producing scaffolds for tissue engineering applications. For the development of this work, the polyesters compounded with chitosan were PBS, PCL, and PBTA. In all of these blends there was a rate of 50\% (wt.\%) chitosan with 50\% (wt.\%) polyester.

The methodology used for the scaffolds production was melt-based compression molding followed by salt leaching. The details of the processing conditions are described elsewhere. ${ }^{33}$ Briefly, the developed blends were grained and the powder mixed with salt particles with size $250 \mu \mathrm{m}<d<$ $500 \mu \mathrm{m}$. The chitosan-based blends mixed with salt were loaded into a mold that was further heated and compression molded into discs. The salt content was $60 \%$ by weight. The discs were cut into $5 \times 5 \times 5 \mathrm{~mm}^{3}$ cubes. These cubes were then immersed in distilled water to leach out the salt, dried, sterilized by ethylene oxide, and used for cell culture studies.

\section{Scaffolds characterization}

The cross section of all the developed scaffolds was analyzed using a Leica-Cambridge S-360 scanning electron microscope (SEM) for preliminary assessment on the scaffolds morphology. All the samples were sputter-coated with gold prior to SEM observations.

To investigate the internal 3D structure of the scaffolds, Micro-Computed Tomography equipment (SkyScan, Kontich, Belgium) was used as a nondestructive technique. Four scaffolds of each condition were scanned in a high-resolution mode of $8.7 \mu \mathrm{m} x / y / z$ and an exposure time of $1792 \mathrm{~ms}$. The energy of the scanner used was $63 \mathrm{keV}$ with $157 \mu \mathrm{A}$ current. $\mu \mathrm{CT}$ scans followed by $3 \mathrm{D}$ reconstruction of serial image sections allowed to analyze 3D microarchitecture of 
the scaffolds, pore morphology, and the determination of the porosity.

Uniaxial compression tests were performed on a square cross-section specimen of scaffolds using a Universal tensile testing machine (Instron 4505 Universal Machine). A crosshead speed of $2 \mathrm{~mm} / \mathrm{min}$ was used. The values reported were the average of at least five specimens. The compressive modulus was determined by selecting the linear region of the stress-strain graph.

Cell culture. A fibroblast cell line of rat lung-L929, acquired from the European Collection of Cell Cultures (ECACC), was used for cytotoxicity tests. The cells were grown as monolayers in Dulbecco's modified Eagle's medium (DMEM; Sigma, St. Louis, MO) supplemented with $10 \%$ foetal bovine serum (FBS; Biochrom, Berlin, Germany) and $1 \%$ of antibiotic-antimycotic mixture $(10,000 \mathrm{U} /$ $\mathrm{mL}$ penicillin $\mathrm{G}$ sodium; $10,000 \mathrm{U} / \mathrm{mL}$ streptomycin sulfate; $25 \mu \mathrm{g} / \mathrm{mL}$ amphotericin B) (Gibco, Invitrogen, Grand Island, NY). Trypsin/EDTA (0.25\%, w/v, trypsin/0.02\% EDTA, Sigma) was used to detach the cells from the culture flasks before the experiments were conducted.

Cell viability assay-MTS test. The ratio of material weight to extract fluid was constant, and equal to $0.25 \mathrm{~g} / \mathrm{mL}$. Latex rubber and standard culture medium were used as positive and negative controls, respectively. Latex rubber is known to have a strong cytotoxic effect leading to extensive cell death. For the positive control, the ratio of material outer surface to extraction fluid was $2.5 \mathrm{~cm}^{2} / \mathrm{mL}$. Test material $(n=6)$ and positive control were extracted for $24 \mathrm{~h}$ at $37^{\circ} \mathrm{C}$, using complete culture medium as extraction fluid. Before the tests, culture medium was removed and an identical volume $(200 \mu \mathrm{L})$ of extraction fluid was added to each well.

Cells were seeded in 96-well plates $(n=6)$ at a density of $1.8 \times 10^{4}$ cells/well and incubated for $24 \mathrm{~h}$ at $37^{\circ} \mathrm{C}$, in a humidified atmosphere with $5 \% \mathrm{CO}_{2}$. A kit (CellTiter 96 One solution Cell Proliferation Assay kit; Promega, Madison, WI) was used, and it is based on the reduction of the substrate, 3(4,5-dimethylthiazol-2-yl)-5(3-carboxymethoxyphenyl)-2(4sulfofenyl)-2H-tetrazolium (MTS), into a brown formazan product by dehydrogenase enzymes active in the viable cells.

After $72 \mathrm{~h}$, the extraction fluid was removed, and $200 \mu \mathrm{L}$ of a serum-free culture medium without phenol red and MTS, in a proportion of 5:1, was added to each well. Cells were then incubated for $3 \mathrm{~h}$ at $37^{\circ} \mathrm{C}$ in a humidified atmosphere containing $5 \% \mathrm{CO}_{2}$. After this time, optical density (OD) was measured with a plate reader (Bio-tek, model Synergy HTi, Winooski, VT) at $490 \mathrm{~nm}$. The OD values obtained were standardized taking into account the values for the negative control.

\section{Cell culture studies}

Cell seeding and culture. A mouse mesenchymal stem cell line (BMC9) was used. This conditionally immortalized MPC clone was shown to exhibit four mesenchymal cell phenotypes: chondrocyte, adipocyte, stromal (support osteoclast formation), and osteoblast. ${ }^{34}$ The cells were grown as monolayer cultures in a culture medium consisting of DMEM medium, 10\% FBS, and $1 \%$ antibiotic/antimycotic mixture. When the adequate cell number was obtained, cells at passage 10 were trypsinized, centrifuged, and resuspended in cell culture medium. Cells were seeded at a density of $5 \times 10^{5}$ cells/scaffold under static conditions, using for this purpose aliquots of $10 \mu \mathrm{L}$ loaded on the top of scaffolds. Two hours after seeding, $1 \mathrm{~mL}$ of culture medium was added to each well. The cell-seeded scaffolds were maintained in a humidified atmosphere at $37^{\circ} \mathrm{C}$, containing $5 \% \mathrm{CO}_{2}$, under osteogenic differentiation inducing medium, during 21 days. The culture medium consisted of DMEM without phenol red, dexamethasone $10^{-8} \mathrm{M}$ (Sigma), ascorbic acid $50 \mu \mathrm{g} / \mathrm{mL}$ (Sigma), and $\beta$-glycerophosphate $10 \mathrm{~mm}$ (Sigma), and was changed every 3-4 days until the end of the experiment.

Cellular viability assay-MTS test. Cell viability was assessed after $3 \mathrm{~h}$ and 7, 14, and 21 days, by using the MTS test. The cell-seeded scaffolds $(n=6)$ were rinsed in $0.15 \mathrm{M}$ phosphate buffered saline (Sigma) and immersed in a mixture consisting of serum-free cell culture medium and MTS reagent at 5:1 ratio and incubated for $3 \mathrm{~h}$ at $37^{\circ} \mathrm{C}$ in a humidified atmosphere containing $5 \% \mathrm{CO}_{2}$. After this, $200 \mu \mathrm{L}$ $(n=6)$ was transferred to 96 -well plates and the optical density (OD) determined at $490 \mathrm{~nm}$.

Cell adhesion and morphology by SEM. Cell adhesion, morphology, and average distribution were observed by SEM. The cell-seeded scaffolds were washed in $0.15 \mathrm{M}$ phosphate buffered saline and fixed in $2.5 \%$ glutaraldehyde in phosphate buffered saline.

After rinsing three times in phosphate buffered saline, the constructs were dehydrated using a series of graded ethyl alcohols (30, 50, 70, 90, and $100 \%$ ethanol) for $15 \mathrm{~min}$ each, twice. Then, the samples were subjected to two changes for $15 \mathrm{~min}$ each with $100 \%$ hexamethyldisilazane (HDMS; Electron Microscopy Sciences, Fort Washington, PA). Finally HDMS was removed and let to air dry for $2 \mathrm{~h}$. Afterward, the constructs were sputter coated with gold (JEOL JFC-1100) and analyzed with a Leica Cambridge S360 scanning electron microscope.

Cell adhesion and cell viability by calcein AM staining through confocal laser microscopy. Cells were incubated with calcein AM (Molecular Probes, Invitrogen). Once inside the cells, this compound is hydrolyzed by endogenous esterase into the highly negatively charged green fluorescent calcein, which is retained in the cytoplasm. The cell-seeded scaffolds were sectioned and cell adhesion, and viability was observed in the inner regions of the scaffolds using an Olympus FluoView FV1000 confocal laser microscope.

Histology. Eight-micrometer-thick sections from the 3week culture of scaffold-cell constructs were cut with a 
cryomicrotome (CM 1900; Leica, Bensheim, Germany) and mounted on poly-L-lysine (Sigma)-coated slides. Slides were stained with $\mathrm{H} \& \mathrm{E}$ and observed under optical microscope.

Alkaline phosphatase quantification. A description of the assay can be found elsewhere. ${ }^{35}$ Briefly, the level of alkaline phosphatase (ALP) activity from the scaffolds/cells constructs $(n=3)$ was quantified by the specific conversion of $p$ nitrophenyl phosphate (pNPP) (Sigma) into $p$-nitrophenol (pNP). The cell-seeded scaffolds were allowed to thaw at room temperature and then were sonicated for roughly $15 \mathrm{~min}$. The enzyme reaction was set up by mixing $100 \mathrm{~mL}$ of the sample with $300 \mathrm{~mL}$ of substrate buffer containing $1 \mathrm{M}$ diethanolamine $\mathrm{HCl}(\mathrm{pH} 9.8)$ and $2 \mathrm{mg} / \mathrm{mL}$ of $\mathrm{pNPP}$. The solution was incubated at $37^{\circ} \mathrm{C}$ for $1 \mathrm{~h}$, and the reaction was then stopped by a solution containing $2 \mathrm{M} \mathrm{NaOH}$ and $0.2 \mathrm{mM}$ EDTA in distilled water. The optical density was determined at $405 \mathrm{~nm}$. A standard curve was made using pNP values ranging from 0 to $20 \mu \mathrm{mol} / \mathrm{mL}$. The results are expressed in micromole of $\mathrm{pNP}$ produced $/(\mathrm{mL} \mathrm{h})$.

Mineralization content by EDS. The constructs were processed as described previously for SEM. The samples were sputter coated with carbon (JEOL JFC-1100), in order to verify the presence of calcium and phosphate elements with a Leica Cambridge S360 electronic microscope.

\section{Statistical analysis}

Statistical evaluation was performed using two-tailed paired Student's $t$-tests to assess the statistical differences between each two groups of different time points. Statistical significance was defined as $p<0.05$ for a $95 \%$ confidence interval.

\footnotetext{
RESULTS

\section{Scaffolds characterization}

The mechanical properties (compressive modulus) of the developed scaffolds are presented in Table 1 . The compressive modulus of the thermally produced scaffolds is in the range of the trabecular bone modulus. ${ }^{36}$

Scaffolds with higher and lower compressive modulus are the ones obtained using the blends chitosan-PBS and chitosan-PBTA, respectively. These results are in accordance with previous results obtained with compact injection molded samples. ${ }^{30}$

Representative $\mu \mathrm{CT}$ images of the entire scaffolds (300 slices) are shown in Figure 1. Three-dimensional reconstructions of the bulk of the scaffolds were also performed. No significant differences in terms of morphology were observed between the more interior parts (bulk) of the scaffolds and the most exterior ones. Two-dimensional X-ray $\mu \mathrm{CT}$ images, with a region of interest of $4.5 \times 4.5 \mathrm{~mm}$, were also analyzed (figure not shown).
}

Table 1. Compressive Modulus and Porosity of the 50 wt. \% Chitosan-Based Scaffolds Produced by Melt-Based Compression Molding with SAlt Leaching $(60 \%$ Salt and GRANULOMETRY OF 250-500 $\mu \mathrm{M}$ )

\begin{tabular}{lcc}
\hline Composition & Compressive modulus $(\mathrm{MPa})$ & Porosity (\%) \\
\hline 50Ch-50PBS & $87.4 \pm 21.6$ & $59.9 \pm 6.5$ \\
50Ch-50PCL & $53.1 \pm 23.7$ & $63.9 \pm 0.7$ \\
50C/50PBTA & $21.8 \pm 7.8$ & $59.4 \pm 3.8$ \\
\hline
\end{tabular}

No significant morphological differences were observed between scaffolds produced using different chitosan-based blends. Pores resulting from the leaching of the $\mathrm{NaCl}$ particles mimic the cubic shape of the porogen used. The scaffolds have a very narrow distribution of pores dimensions coincident with the $\mathrm{NaCl}$ particles size. Two-dimensional binary images were analyzed for total porosity calculations. The porosity values presented in Table 1 are the average of the individual porosity of 300 slices per scaffold. For each processing condition, four scaffolds were analyzed. As expected, porosity depended on the amount of porogen used. In all the cases the porosity was very similar to the amount of salt used.

\section{In vitro cytotoxicity tests}

In the MTS test (Fig. 2), L929 cells produced large amounts of the brown formazan product after incubation with the tested extract. This fact shows that cells had similar metabolic activities (about 80\%) to those obtained by the negative control and were able to incorporate and metabolize MTS, and hence showed their viability. Therefore, the

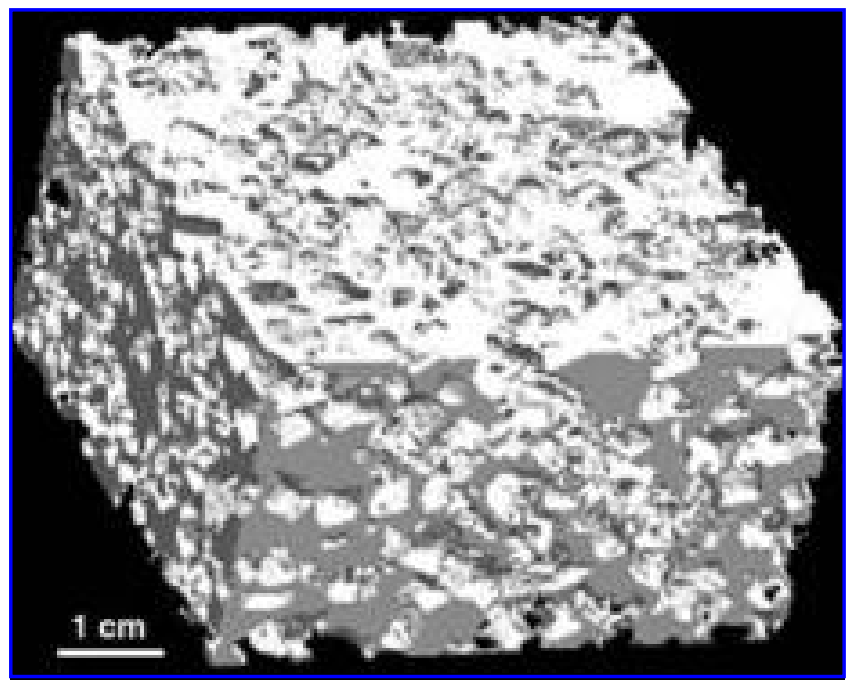

FIG. 1. Representative 3D $\mu \mathrm{CT}$ image of the scaffolds obtained using chitosan-based blends and $\mathrm{NaCl}$ particles with size 250$500 \mu \mathrm{m}$. 


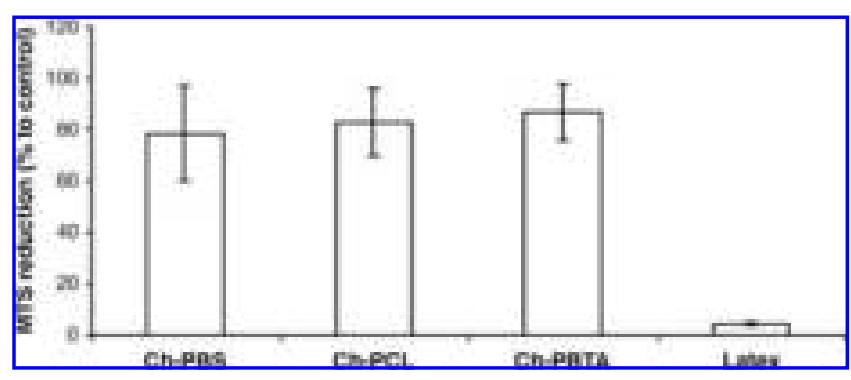

FIG. 2. Cytotoxicity results of the $72 \mathrm{~h}$ extracts of the chitosanPBS, chitosan-PCL, and chitosan-PBTA scaffolds. Results are based on optical density measurements, at OD of $490 \mathrm{~nm}$ and normalized for the negative control $(n=6 ; \pm \mathrm{SD} ; p<0.05)$.

leachables released from the tested scaffolds could be considered as noncytotoxic.

\section{Cell adhesion and morphology by SEM}

Regarding the present experiment, SEM observations allowed to determine that mouse MSCs were able to adhere to the surface of the chitosan-polyester-based scaffolds, where a monolayer of cells could be observed after 1 week in culture (Fig. 3A-C). Further, it should be highlighted that there was no pore occlusion by the cells (Fig. 3D), which demonstrated the adequacy of the pore size range within the scaffolds $(250-500 \mu \mathrm{m})$.
By week 2 it was possible to observe a higher degree of colonization, denoting a multilayer of cells and the onset of elaboration of extracellular matrix (ECM), at the surface of all the scaffolds obtained from different chitosan-based blends (Fig. 3E and F). A closer observation demonstrated that in the blend composed by chitosan and PBS, there was a higher degree of proliferation of the cells, including the ones in the inner regions of the scaffolds (Fig. 3G). Further, by observing the inside scaffold's inner regions (Fig. 4) it was shown that the cells were also capable of colonizing these areas, without occluding the pores of the scaffolds structure.

After 3 weeks, further development of the cell number and surface density were observed, indicating that the BMC 9 cells massively adhered and proliferated within all the chitosanbased scaffolds, also showing a calcified ECM elaboration (Fig. 8).

The scaffolds composed by chitosan-PBS showed cell adhesion and colonization of the surface and inner regions (Fig. 4), and simultaneously evidencing the elaboration of a mineralized extracellular matrix, shown by the presence of $\mathrm{Ca}$ and P, by EDS analysis (Fig. 8A).

\section{Cell viability by MTS assay/calcein AM staining}

Tracking the survival/activity of the cells seeded on the scaffolds from the time of seeding until implantation might be helpful for the optimization on the development of bone tissue-engineered constructs. ${ }^{37}$

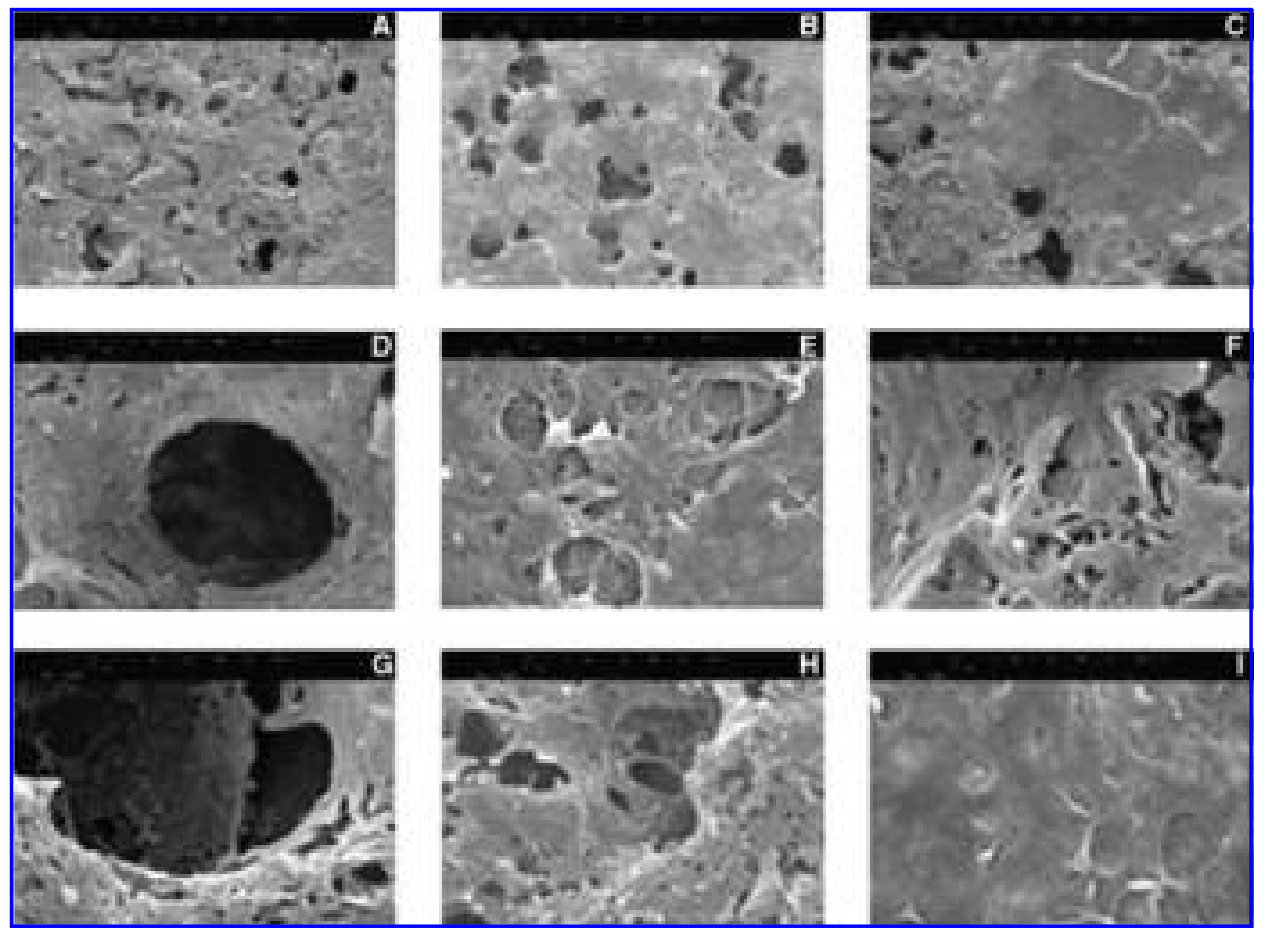

FIG. 3. SEM micrographs of BMC 9 cells adhesion and proliferation, under osteogenic stimulation, on the 50 wt.\% chitosan-PBS scaffolds after (A) 1, (B) 2, and (C) 3 weeks of culture; on the 50 wt.\% chitosan-PCL scaffolds after (D) 1, (E) 2, and (F) 3 weeks of culture; and on the 50 wt.\% chitosan-PCL scaffolds after $(\mathbf{G}) 1,(\mathbf{H}) 2$, and (I) 3 weeks of culture. 


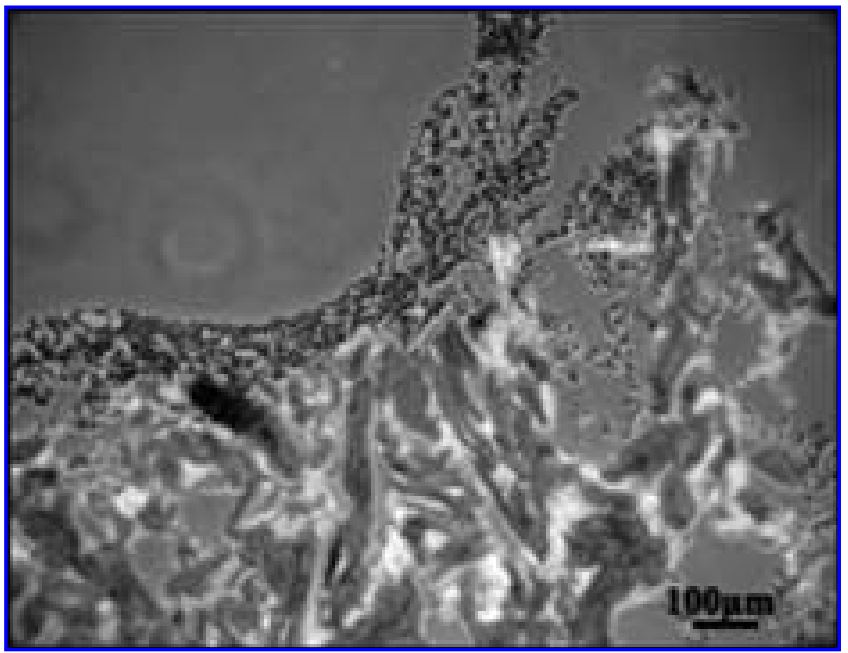

FIG. 4. Light micrograph illustrating a representative section of the colonization of the MSCs onto the chitosan-PBS scaffolds for 21 days, after H\&E staining. Original magnification $100 \times$. Color images available online at www.liebertpub.com/ten.

Results showed that the tested MSCs were able to reduce MTS, showing increasing metabolic rates with increasing time of culture (Fig. 5), and denoting a high viability and proliferation profile. Cell viability assay with calcein AM staining (Fig. 6A-C) confirmed the SEM results, where BMC9 cells were metabolically active in the scaffolds after 3 weeks in static culture. Moreover, with these results it can be established a time-dependent cell proliferation, as it is notorious the presence of a higher number of cells for the latest time period.

\section{Alkaline phosphatase quantification}

For all tested blends, ALP activity (Fig. 7) increased until the second week, reflecting probably the early osteogenic differentiation stage of the MSCs. After this period, ALP activity decreased, presumably due to the onset of the mineralization process, ${ }^{36}$ denoting in this sense a positive indication of the transient character of the differentiation of

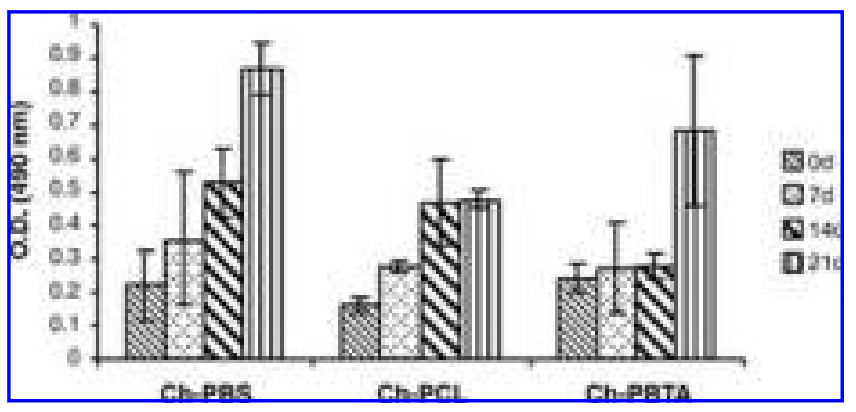

FIG. 5. Viability of the BMC9 cells seeded and cultured onto the chitosan-PBS (ch-PBS), chitosan-PCL (ch-PCL), and chitosanPBTA (ch-PBTA) scaffolds following $3 \mathrm{~h}$ after cell seeding, at 1 , 2 , and 3 weeks, by MTS assay $(n=6 ; \pm \mathrm{SD} ; p<0.05)$. the cells into the osteogenic lineage. Once more, the best results were evidenced by the scaffolds produced from the chitosan-PBS blend, which showed the higher values of the ALP activity.

\section{Mineralization content by EDS analysis}

The EDS analysis of the surface of the seeded and cultured scaffolds with mouse MSCs under osteogenic conditions for 21 days (Fig. 8) detected the presence of $\mathrm{Ca}$ and $\mathrm{P}$ elements on the surface, being therefore, a clear indication of the formation of a mineralized ECM.

\section{DISCUSSION}

In the last few years, natural-based polymers have been presented as biomaterials for tissue-engineered scaffolding. Among these, chitosan has emerged as one of the most promising, namely, by its biodegradability, its biocompatibility, and its resemblance to glycosaminoglycans. ${ }^{28}$

In this study we report the biological performance, in terms of cell adhesion, proliferation, and differentiation of mouse MSCs seeded and cultured onto the newly developed chitosan-based scaffolds.

The melt-based approach used to produce the scaffolds allowed us to obtain 3D porous structures without the use of organic solvents that could remain in the structure and damage the transplanted cells or the surrounding tissues (after transplantation). The mechanical properties, in terms of compressive modulus, were in the range of those for trabecular bone properties. ${ }^{36}$

The developed scaffolds revealed to be noncytotoxic to fibroblast cells, since the leachables released during the extraction period did not affect cell viability and did not inflict changes in cell morphology.

Cells were able to colonize the scaffolds structure up to 3 weeks. The cell proliferation was gradual and continuously increasing over time of culture, being more evident on the chitosan-PBS scaffolds. The differences observed for the different blends are probably related with the different surface chemistry and mechanical properties of the 3D scaffolds, with the best results being noticed for the scaffolds produced from chitosan-PBS blend.

It is known that if cells are undergoing osteogenic differentiation, ALP is considered to be one of the early markers. ${ }^{38}$ Although not being specific for the osteoblast lineage, ALP is used typically to illustrate the early differentiation into a bone-related phenotype, which is noticed by the increase of the enzyme activity until the second week.

The presence of $\mathrm{Ca}$ and $\mathrm{P}$ elements on the surface of the cell-seeded scaffolds revealed the presence of a mineralized ECM. This fact is in agreement with the data obtained for alkaline phosphatase experiments, showing that cells had undergone an osteogenic differentiation and were elaborating mineralized ECM. 


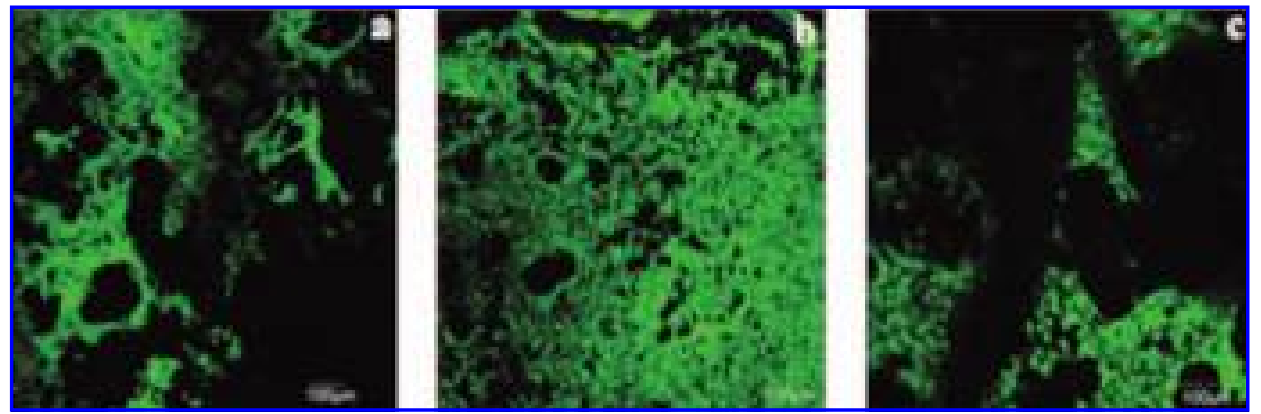

FIG. 6. Confocal micrographs showing the cell adhesion and viability upon the scaffolds of 50 wt.\% chitosan-PBS scaffolds (A), 50 wt. $\%$ chitosan-PCL scaffolds (B), and 50 wt.\% chitosan-PBTA scaffolds (C), after 3 weeks of culture. Color images available online at www.liebertpub.com/ten.

\section{CONCLUSIONS}

With the present study it was possible to show that the scaffolds based on 50:50 wt.\% blends of chitosan and synthetic polyesters (PBS, PCL, and PBTA) present a range of properties that are considered to be adequate for bone tissue engineering applications.

Scaffolds produced by compression molding followed by salt leaching were shown to be noncytotoxic and clearly cytocompatible. The results of the direct contact assays under osteogenic conditions revealed that the three types of chitosan-based scaffolds selected for this study promoted the attachment and proliferation of mouse mesenchymal stem cells. Further, they also presented high indexes of alkaline phosphatase activity and the production of a calcified ECM, which is due to the differentiation toward the osteogenic pathway. From the three tested blends, the chitosan-PBS blend showed the best results, namely, in terms of cell adhesion and proliferation. Nevertheless, the other blends also presented adequate properties for bone tissue engineering.

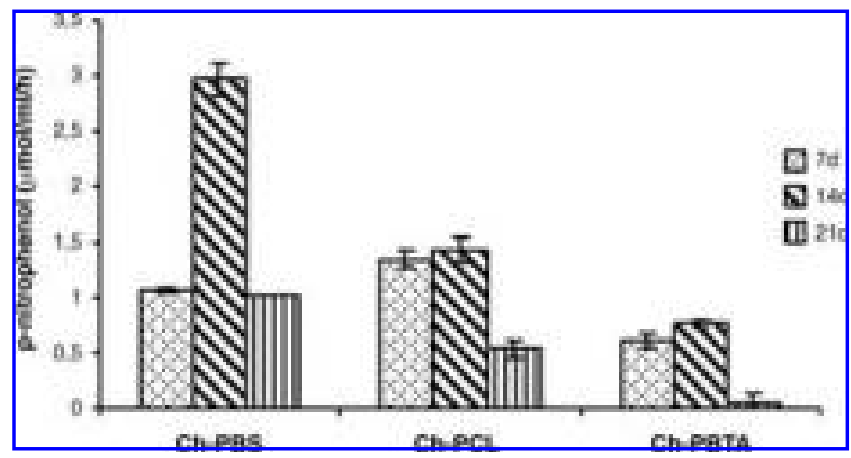

FIG. 7. Alkaline phosphatase activity assay: supernatants were weekly collected and frozen. After 3 weeks, supernatants were thawed. The results are shown in $p$-nitrophenol $(\mu \mathrm{mol} / \mathrm{mL} / \mathrm{h})$ as a function of days. On day 7, cells were stimulated with $10 \mathrm{mM}$ glycerophosphate(Sigma), $50 \mathrm{mMascorbic}$ acid(Sigma), and $10^{-8} \mathrm{M}$ dexamethasone (Sigma). The ALP levels increased, reaching the highest values after 2 weeks in culture $(n=6 ; \pm \mathrm{SD} ; p<0.05)$.
Due to the good combination of properties and excellent biological performance, it is strongly believed that the scaffolds herein proposed will be a valid alternative to the currently used materials when considering bone regeneration/ tissue engineering applications.

\section{ACKNOWLEDGMENTS}

Ana Costa-Pinto was supported by the scholarship SFRH/24735/2005 from the Portuguese research council "Fundação para a Ciência e a Tecnologia" (FCT).

This work was partially supported by the EU Integrated Project GENOSTEM (Adult Mesenchymal Stem Cells Engineering for Connective Tissue Disorders: From the Bench to the Bed Side) and the European Network of Excelence EXPERTISSUES. The authors would like to acknowledge to the Institute for Health and Life Sciences of

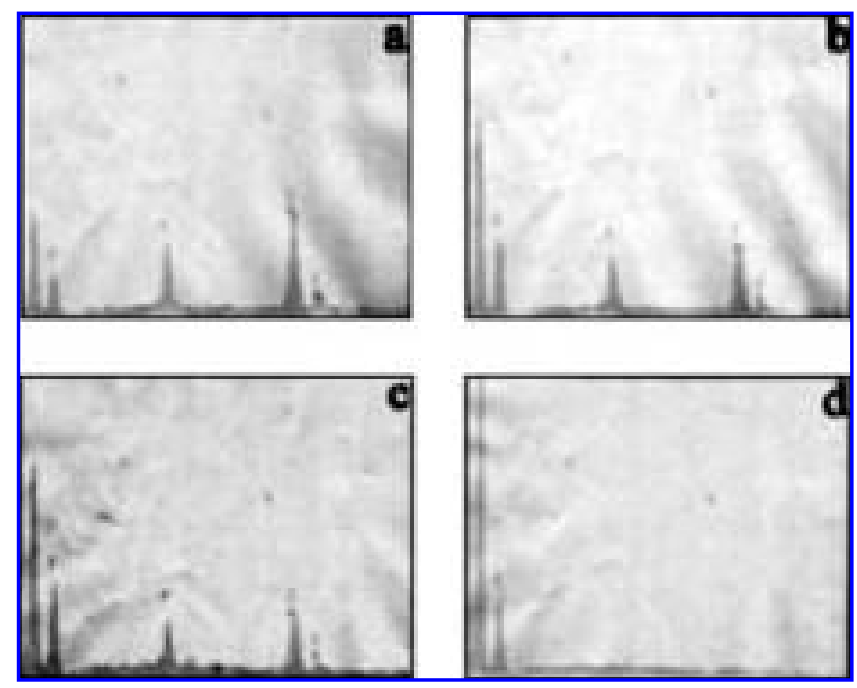

FIG. 8. Energy dispersive spectra showed the presence of calcium and phosphorous at the surface of the seeded chitosan-PBS (A), chitosan-PCL (B), and chitosan-PBTA (C), and unseeded (D) scaffolds after 3 weeks under osteogenic culture conditions. 
University of Minho, Braga, Portugal, for allowing the use of their research facilities.

\section{REFERENCES}

1. Langer, R., and Vacanti, J.P. Tissue Engineering. Science 260, 920, 1993.

2. Yang, S., Leong, K., Du, Z., and Chua, C. The design of scaffolds for use in tissue engineering. Part I. Traditional factors. Tissue Eng 7(6), 679, 2001.

3. Salgado, A.J., Gomes, M.E., Reis, R.L. Tissue engineering of mineralized tissues: the essential elements. In: Reis, R.L., Weiner, S., eds. Learning from Nature How to Design New Implantable Biomaterials: From Biomineralization Fundamentals to Biomimetic Materials and Processing Routes. NATO/ASI Series. Kluwer Press, 2004, pp. 205-222.

4. Kneser, U., Schaefer, D.J., Munder, B., Klemt, C., Andree, C., and Stark, G.B. Tissue engineering of bone. Minimal Invasive Ther Allied Technol 11, 107, 2002.

5. Albrektsson, T., and Johansson, C. Osteoinduction, osteoconduction and osseointegration. Eur Spine J 10, 96, 2001.

6. Lind, M., and Bunger, C. Factors stimulating bone formation. Eur Spine J 10, 102, 2001.

7. Salgado, A.J., Coutinho, O.P., Reis, R.L. Bone tissue engineering: state of the art and future trends. Macromol Biosci 4(8), 743, 2004.

8. Mano, J.F., Sousa, R.A., Boesel, L.F., Neves, N.M., Reis, R.L. Bioinert, biodegradable and injectable polymeric matrix composites for hard tissue replacement: state of the art and recent developments. Compos Sci Technol 64, 789, 2004.

9. Sikavitsas, V.I., Van den Dolder, J., Bancroft, G.N., Jansen, J.A., and Mikos, A.G. Influence of the in vitro culture period on the in vivo performance of cell/titanium bone tissue. Engineered constructs using a rat cranial critical size defect model. J Biomed Mater Res 67(3), 944, 2003.

10. Holtorf, H.L., Jansen, J.A., and Mikos, A.G. Ectopic bone formation in rat marrow stromal cell/titanium fiber mesh scaffolds constructs: effect of initial cell phenotype. Biomaterials 26, 6208, 2005.

11. Meretoja, V.V., De Ruijter, A.E., Peltola, T.O., Jansen, J.A., and Narhi, T.O. Osteoblast differentiation with titania and titania-silica-coated titanium fiber meshes. Tissue Eng 11 (9-10), 1489, 2005.

12. Okamoto, M., Dohi, Y., Ohgushi, H., Shimaoka, H., Ikeuchi, M., Matsushima, A., Yonemasu, K., and Hosoi, H. Influence of the porosity of hydroxyapatite ceramics on in vitro and in vivo bone formation by cultured rat bone marrow stromal cells. J Mater Sci Mater Med 17(4), 327, 2006.

13. Le Nihouannen, D., Guehennec, L.L., Rouillon, T., Pilet, P., Bilban, M., Layrolle, P., and Daculsi, G. Micro-architecture of calcium phosphate granules and fibrin glue composites for bone tissue engineering. Biomaterials 27(13), 2716, 2006.

14. Petite, H., Viateau, V., Bensaid, W., Meunier, A., de Pollak, C., Bourguignon, M., Oudina, K., Sedel, L., and Guillemin, G. Tissue-engineered bone regeneration. Nat Biotechnol 18(9), 959, 2000.

15. Ishaug, S.L., Crane, G.M., Miller, M.J., Yasko, A.W., Yaszemski, M.J., and Mikos, A.G. Bone formation by three- dimensional stromal osteoblast culture in biodegradable polymer scaffolds. J Biomed Mater Res 1, 17, 1997.

16. Schantz, J.T., Hutmacher, D.W., Chim, H., Ng, K.W., Lim, T.C., and Teoh, S.H. Induction of ectopic bone formation by using human periosteal cells in combination with a novel scaffold technology. Cell Transplant 11(2), 125, 2002.

17. Mendes, S.C., Bezemer, J., Claase, M.B., Grijpma, D.W., Bellia, G., Degli-Innocenti, F., Reis, R.L., de Groot, K., van Blitterswijk, C.A., and De Bruijn, J.D. Evaluation of two biodegradable polymeric systems as substrates for bone tissue engineering. Tissue Eng 9, 91, 2003.

18. Miroslav, P., Mano, J.F., Neves, N.M., Reis, R.L., Fibers and 3D mesh scaffolds from biodegradable starch-based blends: production and characterization. Macromol Biosci 4(8), 776, 2004.

19. Hutmacher, D.W. Scaffolds in tissue engineering bone and cartilage. Biomaterials 21, 2529, 2000.

20. Behravesh, E., Yasko, A., Engel, P., and Mikos, A.G. Synthetic biodegradable polymers for orthopaedic applications. Clin Orthop 367, 118, 1999.

21. Gomes, M.E., Ribeiro, A.S., Malafaya, P.B., Reis, R.L., and Cunha, A.M. A new approach based on injection moulding to produce biodegradable starch based polymeric scaffolds. Biomaterials 22, 883, 2001.

22. Marques, A.P., Reis, R.L., and Hunt, J.A. Cytokine secretion from mononuclear cells cultured in vitro with starch-based polymers and poly-L-lactide. J Biomed Mater Res A 71(3), 419, 2004.

23. Malafaya, P.B., Pedro, A.J., Peterbauer, A., Gabriel, C., Redl, H., and Reis, R.L. Chitosan particles agglomerated scaffolds for cartilage and osteochondral tissue engineering approaches with adipose tissue derived stem cells. J Mater Sci Mater Med 16(12), 1077, 2005.

24. Zhang, Y., Ni, M., Zhang, M., and Ratner, B. Calcium phosphate-chitosan composite scaffolds for bone tissue engineering. Tissue Eng 9(2), 337, 2003.

25. Seol, Y.J., Lee, J.Y., Park, Y.J., Lee, Y.M., Young-Ku, Rhyu, I.C., Lee, S.J., Han, S.B., Chung, C.P. Chitosan sponges as tissue engineering scaffolds for bone formation. Biotechnol Lett 26(13), 1037, 2004.

26. Yin, Y.J., Luo, X.Y., Cui, J.F., Wang, C.Y., Guo, X.M., and Yao, K.D. A study on biomineralization behavior of $N$-methylene phosphochitosan scaffolds. Macromol Biosci 4(10), 971, 2004.

27. Ding, Z., Chen, J., Gao, S., Chang, J., Zhang, J., and Kang, E.T. Immobilization of chitosan onto poly-lactic acid film surface by plasma graft polymerization to control the morphology of fibroblast and liver cells. Biomaterials 25, 1059, 2004.

28. Di Martino, A., Sittinger, M., and Risbud, M.V. Chitosan: a versatile biopolymer for orthopaedic tissue-engineering. Biomaterials 26(30), 5983, 2005.

29. Oliveira, J.M., Rodrigues, M.T., Silva, S.S., Malafaya, P.B., Gomes, M.E., Viegas. C.E., Dias, I.R., Azevedo, J.T., Mano, J.F., and Reis, R.L. Novel hydroxyapatite/chitosan bilayered scaffold for osteochondral tissue-engineering applications: scaffold design and its performance when seeded with goat bone marrow stromal cells. Biomaterials 27, 6123, 2006.

30. Correlo, V.M., Boesel, L., Bhattacharya, M., Mano, J.F., Neves, N.M., and Reis, R.L. Properties of melt processed chitosan and aliphatic polyester blends. Mater Sci Eng A 403(1-2), 57, 2005. 
31. Correlo, V.M., Boesel, L., Bhattacharya, M., Mano, J.F., Neves, N.M., and Reis, R.L. Hydroxyapatite reinforced chitosan and polyester blends for biomedical applications. Macromol Mater Eng 290(12), 1157, 2005.

32. Correlo, V.M., Pinho, E., Pashkuleva, I., Bhattacharya, M., Neves, N.M., and Reis, R.L. Water absorption and degradation characteristics of chitosan-based polyesters and hydroxyapatite composites. Macromol Biosci 7, 354, 2007.

33. Correlo, V.M., Boesel, L.F., Pinho, E., Bhattacharya, M., Mano, J.F., Neves, N.M., and Reis, R.L. Melt based compression molded scaffolds from chitosan-based blends and composites: morphology and mechanical properties. J Biomed Mater Res Part A (In press).

34. Dennis, J.E., Merriam, A., Awadallah, A., Yoo, J.U., Johnstone, B., and Caplan, A.I. A quadripotential mesenchymal progenitor cell isolated from the marrow of an adult mouse. JBMR 14, 700, 1999.

35. Maniatopoulos, C., and Sodek, J.M. Bone formation in vitro by stromal cells obtained from bone marrow of young adult rats. Cell Tissue Res 254, 317, 1988.

36. Aubin, J.E., and Liau, F. Principles of Bone Biology, 1st ed. Academic Press, 1996, p. 51.
37. Wilson, C.E., Dhert, W.J.A., Van Blitterswijk, C.A., Verbout, A.J., and De Bruijn, J.D. Evaluation of 3D bone tissue engineered constructs with different seeding densities using the alamarBlue $^{\mathrm{TM}}$ assay and the effect of in vivo bone formation. J Mater Sci Mater Med 13, 1265, 2002.

38. Lian, J.B., and Stein, G.S. Concepts of osteoblast growth and differentiation: basis for modulation of bone cell development and tissue formation. Crit Rev Oral Biol Med 3, 269, 1992.

Address reprint requests to: Ana Rita Costa-Pinto, B.Sc. 3B's Research Group-Biomaterials, Biodegradables and Biomimetics Department of Polymer Engineering University of Minho Campus de Gualtar 4710-057 Braga Portugal

E-mail: arpinto@dep.uminho.pt 
